\title{
Analysis on the Leveling Capacity of an 11-roll Leveler in 2250 Cross Cutting Line
}

\author{
Xiaobin $\mathrm{Ma}^{1, \mathrm{a}^{*}}$, Jie Zhang ${ }^{1, \mathrm{~b}}$, Hongbo $\mathrm{Li}^{1, \mathrm{c}}$, Yizhong Zhou ${ }^{2, \mathrm{~d}}$, Weidong $\mathrm{Hu}^{2, \mathrm{e}}$ and \\ Ansu Wang ${ }^{2, f}$ \\ ${ }^{1}$ School of Mechanical Engineering, University of Science and Technology Beijing, Beijing, China \\ ${ }^{2}$ Hot Rolling Mill, Wuhan Iron \& Steel (Group) Corp., Wuhan, Hubei, China \\ austb_max@163.com, bzhangjie@ustb.edu.cn, ${ }^{\mathrm{a}}$ lihongbo@ustb.edu.cn, leafwu@263.net, \\ ewuhanhuweidong@sina.com, ${ }^{\mathrm{f}}$ ansuw_wu@163.com
}

Keywords: 11-roll leveler; leveling capacity; total leveling force; motor power.

Abstract. Many problems have occurred in using an 11-roll leveler in 2250 cross cutting line due to the increasing maximum strength of hot rolled coil. To determine the cause of these problems, a model to calculate the leveling capacity quickly is constructed using leveler's structural parameters and force-energy parameters, and then a contrastive analysis is made between the calculated results and the design capacity. The influence of strength coefficient and leveling speed on leveling capacity is also investigated.

\section{Introduction}

Roller leveling machine is the main and key equipment in cross cutting line used to improve plate and strip products ${ }^{[1]}$. In order to meet user's needs of moderately thick steel plate and increase the strength and varieties of domestic plate products, steel mills introduce a batch of heavy gauge cross cutting line that configure advanced mighty leveler in China in recent years ${ }^{[2][3]}$. However, due to the lightweight of vehicle body and more profit which steel mills wanted, cross cutting line needs to deal with more and more high-strength steel plate which is close to the leveling capacity border. This leads to various problems in production, such as production line instability, production drawdown and high product defect rate, which become the bottleneck of steel mills to increase the output of high-strength steels.

To find out the cause of these problems which occurred in leveling high-strength steel plate using an 11-roll leveler in 2250 cross cutting line and analyze the determining principle of its capacity border, a model to determine the leveling capacity border quickly is constructed using the expected plastic ratio and the maximum mechanical parameters ${ }^{[4]}$. According to the model, leveling capacity curves of an 11-roll leveler are drawn, which can be used to judge whether the incoming plate can be leveled. This model can provide theoretical foundation for setting reasonable roller gap.

\section{Limiting factors of leveling capacity}

The capacity of specific roller leveler is definite and limited and it is mainly affected by these factors, such as its structure, the allowable maximum total leveling force and motor rated power. In general, the capacity border of a leveler can be drawn by the following parameters, and then the capacity border can be used to quickly judge whether the income can be leveled.

Total leveling force

The maximum reduction force, which is produced by hydraulic cylinders, is a constant. So the total leveling force in leveling process must be less than the leveler's maximum reduction force.

$$
F_{\Sigma}=0.5 \square \sum_{i=1}^{N} F_{i} \leq F_{\max }
$$


Where $F_{\Sigma}$ is the total leveling force, $N$ is the number of rollers, $F_{i}$ is the leveling force on single roller as shown in Fig. 1, $F_{i}=2\left(M_{i-1}+2 M_{i}+M_{i+1}\right) / p, M_{i}$ is the internal moment of the plate under the roller i, $p$ is the roller pitch, $F_{\max }$ is the leveler's maximum reduction force.

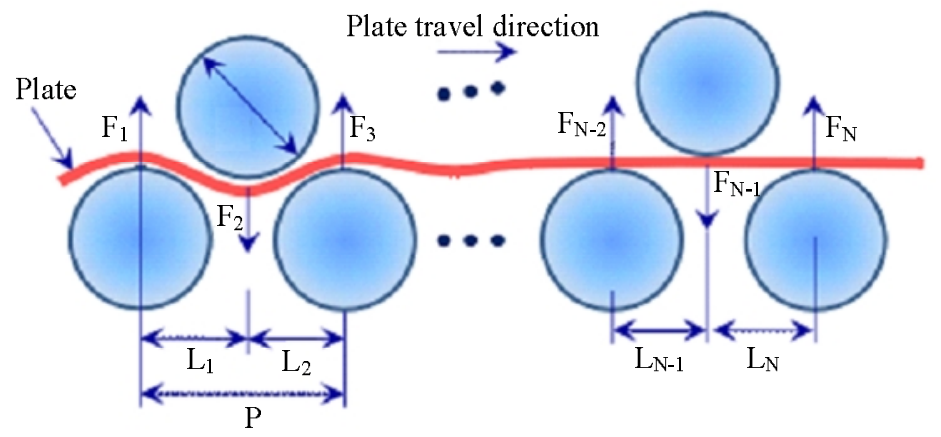

Fig. 1 force distribution during leveling

This limiting factor can be summarized as

$$
F_{\Sigma}=\frac{4 M_{t}}{p} \sum_{i=2}^{N-1} \bar{M}_{i} \leq F_{\max }
$$

Where $M_{t}$ is the elastic limit bending moment, $M_{t}=B H^{2} \sigma_{s} / 6, \bar{M}_{i}$ is the bending moment ratio under the roller $\mathrm{i}$.

\section{Motor power}

The rated power of the motor installed in the leveler is fixed, so the power required in leveling process is not greater than the motor rated power.

$$
P_{\Sigma}=\sum_{i=1}^{N}\left[F_{i}\left(f+\frac{\mu d}{2}\right)+u_{J i} \frac{D}{2}\right] \frac{2 v}{\eta D} \leq P_{\text {Moter }}
$$

Where $P_{\Sigma}$ is the power required in the leveling process, $f$ is the rolling friction coefficient between roller and plate, $\mu$ is the friction coefficient between the roller journal and the bearing, $d$ is the roller journal diameter, $D$ is the roller diameter, $v$ is the leveling speed, $u_{J i}$ is the plastic energy in per length of the plate. $u_{J_{i}}=\frac{B H \sigma_{s}^{2}}{6 E}\left\{(1-\lambda)\left[\frac{3}{\zeta}-3+\zeta-(1-\lambda) \cdot m^{2}-\frac{2 \lambda}{\zeta} \cdot m\right]+\frac{\lambda}{\zeta}\left(\zeta-2+\frac{2-\zeta}{\zeta}\right)\right\}$, $\lambda$ is the strength coefficient, $\zeta$ is the elastic ratio, $m=1.5-0.5 \zeta^{2}, \eta$ is the total efficiency of the transmission system.

Expected deformation plastic ratio

The plastic deformation ratio which equals to $1-\zeta$, is an important parameter in the leveling process $^{[5][6]}$. The quality of the plate will be improved if the plastic deformation ratio increases to $70 \% \sim 80 \%(\zeta=20 \% \sim 30 \%)$. The plate cannot be leveled well if the plastic deformation ratio is less than the expected value even though it is winded around the rollers. So the geometry model of expected deformation plastic ratio can be summarized as

$$
A_{w}=\frac{A_{t}}{\zeta} \leq \frac{1}{R}
$$

Where $A_{w}$ is the bending curvature, $A_{t}$ is the elastic limit curvature, $A_{t}=2 \sigma_{s} / E H$. Contact strength of leveling roll 
Contact stress between roller and plate is large and harmful. The contact stress may cause roller fatigue damage when it exceeds the allowable contact stress of roller. The contact between roller and plate can be simplified into the contact model between the cylinder and the plane. According to the Hertz contact theory this factor can be written as

$$
\sigma_{j \max }=0.418 \sqrt{\frac{F E}{B R}} \leq\left[\sigma_{j}\right]
$$

Where $\sigma_{j \max }$ is the maximum contact stress, $F$ is the maximum leveling force, $F=8 \bar{M}_{\max } M_{t} / p$.

\section{Determination of leveling capacity border}

The conditions of an 11-roll leveler which has a problem with leveling high strength steel plate are listed in Table 1. The parameters such as $f, \mu, \eta$ of this leveler are constants, the values of them are $0.0002 \mathrm{~m}, 0.005,0.7$, respectively ${ }^{[7]}$. Simulation results are obtained under the speed of 18 $\mathrm{m} / \mathrm{min}$ using the four equations (2)-(5). It can be seen from Fig. 2 that the leveling capacities are a series of family curves.

Table 1 Equipment parameters of 11-roll leveler

\begin{tabular}{lc||lc}
\hline Parameter name & Parameter value & Parameter name & Parameter value \\
\hline Number of rollers & 11(top:5,bottom:6) & Roller diameter [mm] & 220 \\
Roller pitch [mm] & 230 & Jounal diameter $/ \mathrm{mm}$ & 120 \\
Maximum total & 24000 & Allowable contact & 1020 \\
leveling force $[\mathrm{kN}]$ & & stress [Mpa] & \\
Motor power $[\mathrm{kW}]$ & $2 * 250+110$ & Maximum leveling & 45 \\
Plate width $[\mathrm{mm}]$ & 2100 & speed $[\mathrm{m} / \mathrm{min}]$ & \\
\hline
\end{tabular}

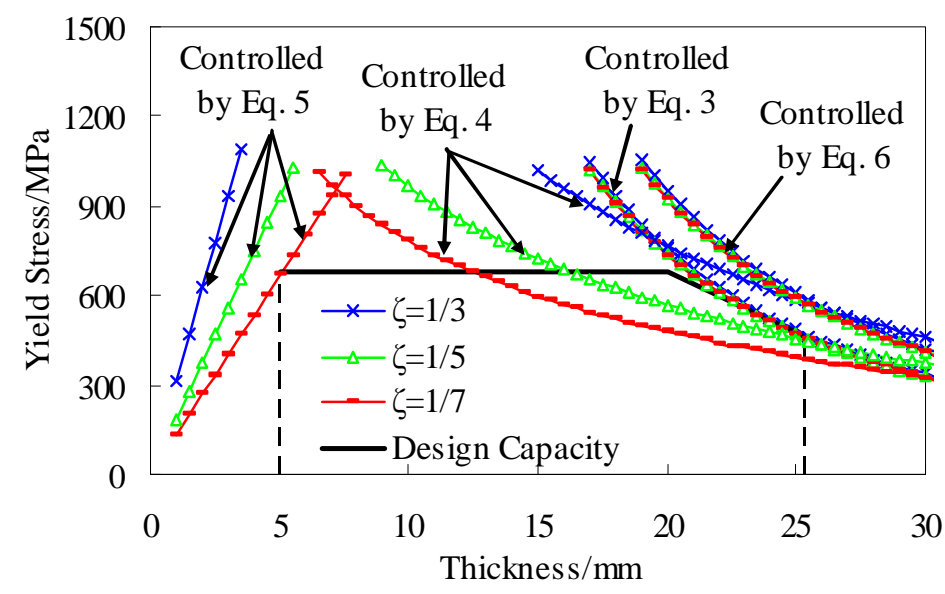

Fig. 2 Leveling capacity border curves

It can be seen from Fig. 2 that the smaller the elastic ratio is, the narrower the leveling range is. As for the ultimate strength of plate in a certain thickness, the one determined by contact strength is higher than that of total leveling force, which means that any of the curves is surrounded by three parts. When comparing the design capacity of this leveler with the simulation results it can be seen clearly: 
a. With the increase of thickness, the total power needed in leveling high strength plate is larger than the allowable value of the machine. That can be avoided by reducing the plastic ratio or changing higher-powered motor.

b. With the decrease of thickness, high strength plate needs bigger reduction at a certain plastic ratio and leads to biting difficultly. That situation can be improved by enlarging sent entrance force and choosing a suitable plastic ratio.

c. In the middle of thickness range (about $8 \mathrm{~mm}$ ), this leveler has the potential to level higher strength steel plate.

The established model is used to research the influence of strength coefficient and leveling speed on the leveling capacity, as shown in Fig. 3, the elastic is 1/5 here. It can be seen form Fig. 3 that the capacity range narrows down with the increase of speed and strength coefficient, and the result is more different due to leveling speed than strength coefficient.

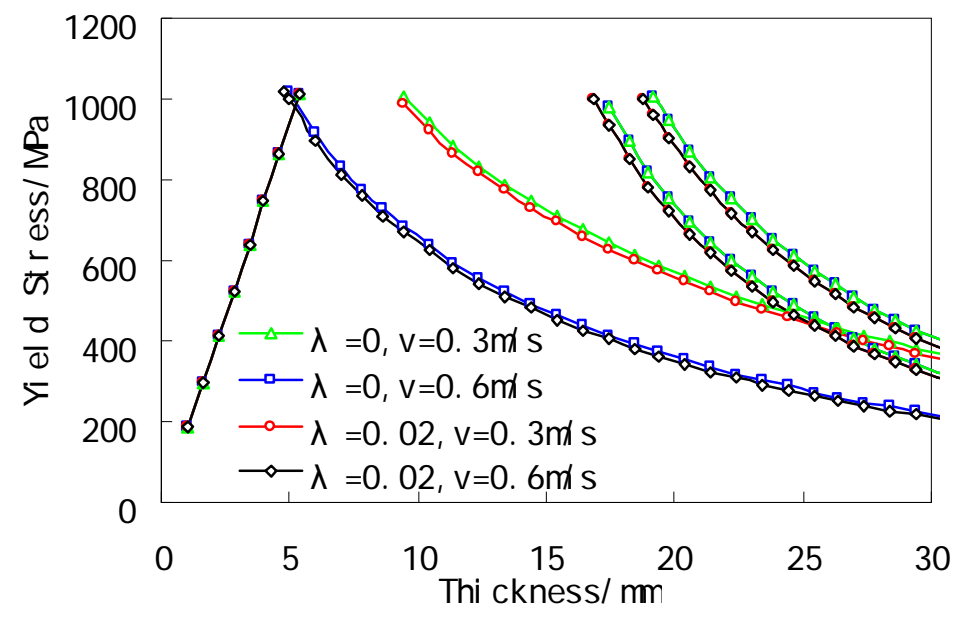

Fig. 3 Leveling capacity curves under different conditions

\section{Conclusions}

a. The leveling capacity model is constructed and its simulation result is compared with the design capacity. Features of the leveling capacity range are obtained from the comparison.

b. The influence of plastic ratio, strength coefficient, leveling speed on the capacity is studied. The research results indicate that the greater the speed and strength coefficient are, the smaller the leveling capacity is.

c. Possible leveling parameters of a plate can be determined quickly and conveniently for given shape and material properties.

\section{References}

[1] Guodong Wang, Xianghua Liu. Steel Rolling. 24(1) (2007) 1-6. (in Chinese)

[2] Y.N. Belobrov, V.G. Smirnov, A.I. Titarenko. Metallurgist. 46(9/10) (2002) 280-283.

[3] Li Cui, Xianlei Hu, Qiang Guo. Journal of Northeastern University (Natural Science) . 32(5) (2011) 671-674. (in Chinese)

[4] Yongqin Wang, Zhifang Liu, Xingchun Yan. Jounal of Central South University. 19(9) (2012) 2477-2481.

[5] A. Matsuo, M. Fujita. Iron \& Steel Institute of Japan Journal. 19(2) (2006) 327-330. (in Japanese) 
[6] A. Matsuo, S. Yoshikazu. Iron \& Steel Institute of Japan Journal. 15(5) (2002) 1010. (in Japanese)

[7] Fu Cui, Straightening and straightening machine, second ed., Metallurgical Industry Press, Beijing, 2005. (in Chinese) 